\title{
Plasma irradiation effects in phthalocyanine films
}

\author{
G.L. Pakhomov*, M.N. Drozdov, N.V. Vostokov \\ Institute for Physics of Microstructures of the Russian Academy of Sciences, Nizhny Novgorod, \\ GSP-105, Nizhny Novgorod 603950, Russia
}

Received in revised form 16 February 2004; accepted 18 February 2004

Available online 30 April 2004

\begin{abstract}
Plasma irradiation effects in copper phthalocyanine films were examined. The film surface and chemical composition were characterized by means of atomic force microscopy (AFM) and secondary ion mass spectrometry (SIMS), including SIMS profiling.

(C) 2004 Elsevier B.V. All rights reserved.
\end{abstract}

PACS: 61.66.Hq; 81.65.Cf; 68.49.Sf; 81.07.Pr

Keywords: Phthalocyanines; Dry etching; SIMS; AFM; Heterostructures

\section{Introduction}

A great deal of effort is going currently into extending the use of organic and/or composite materials to (opto-)electronics to replace conventional inorganic matter (e.g. III-V or Si-based semiconductors) [1]. In pursuit of the ultimate goal of this activity, which is single-molecule (nano-) devices [2], the stage of micro-technology development is often skipped over. As a result, such common and well-developed techniques as patterning, plasma, ion treatment and implantation, are much less known in the field of molecular electronics. Meanwhile, metal phthalocyanines (PcM) that feature superior chemical and thermal stability among organic substances seem to be very likely candidates for fabricating hybrid inor-

\footnotetext{
* Corresponding author. Tel.: +7-8313-675535; fax: +7-8313-675553.

E-mail address: pakhomov@ipm.sci-nnov.ru (G.L. Pakhomov).
}

ganic/organic devices, which exploit fascinating electrical and optical activity of these complexes [3].

In the present study we report some results of plasma modification of $\mathrm{PcCu}$ films in the reactive ion etching (RIE) chamber. The attention was focused to the general behavior of the material exposed under ion bombardment, rather than on the changes in the electrical or optical properties of such materials. We tested $\mathrm{O}_{2}, \mathrm{He}$ and $\mathrm{Ar}$ (which is of not much difference) and $\mathrm{CCl}_{2} \mathrm{~F}_{2}$ since combination of such chemistries may be useful for processing of PcM-based heterostructures containing inorganic components. For instance, $\mathrm{O}_{2}$ is often utilized for resist stripping [4], while $\mathrm{CCl}_{2} \mathrm{~F}_{2} / \mathrm{He}(\mathrm{Ar})$ chemistries are effective for selective patterning of III-V heterostructures [5,6].

The energies of ions in a conventional RIE reactor typically correspond to tens electron volts or less [7]. This is comparable with the energies of chemical bonds in phthalocyanine molecules and by far higher than the van der Waals forces forming the molecular 
crystallites. Therefore, severe alterations both in the film composition and morphology are predictable. Contribution of a local thermal stress cannot be underestimated. In lead phthalocyanine films for example, such processes as formation of new chemical bonds, polymerization, remarkable changes in relative atomic concentration of elements in the film surface and its restructuring were detected after plasma treatment [13]. Earlier, similar effects were observed for ion beam implantation in thin polycrystalline phthalocyanine films [8], although the energy of penetrating metal ions corresponded to several tens $\mathrm{keV}$, and the average projected ranges lay far in the film bulk. It is however expected that reactive or non-reactive ions and their combination will cause different effects on the film surface.

\section{Experimental}

Copper phthalocyanine, $\mathrm{C}_{32} \mathrm{H}_{16} \mathrm{~N}_{8} \mathrm{Cu}$ or $\mathrm{PcCu}$ (pigment blue, commercial polycrystalline powder), whose molecular structure is shown in Fig. 1, was thermally evaporated onto $\operatorname{Si}\left(\begin{array}{lll}1 & 1 & 1\end{array}\right)$ plates in vacuum $<10^{-3} \mathrm{~Pa}$ (VUP-5 installation). The obtained heterostructures were also used in other physical experiments [8]. The organic film thickness was equal to $0.8 \pm 0.2 \mu \mathrm{m}$ at the deposition rate of $0.2-0.4 \mathrm{~nm} / \mathrm{s}$. The samples were stored in laboratory air prior to further processing and measurements. Plasma treatment of the $\mathrm{PcCu}$ films was performed in a conventional planar RIE system (Secon XPL-26) equipped with a $100 \mathrm{kHz}$ rf generator. The etcher had an anodized aluminium reaction chamber with symmetric temperature controlled electrodes spaced $25 \mathrm{~mm}$ apart. The samples were positioned on the bottom rf-driven electrode. The gas inlet was implemented

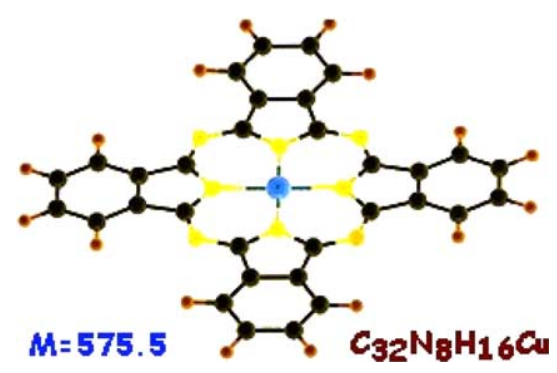

Fig. 1. Molecular structure of $\mathrm{PcCu}$. through five small orifices surrounding the cathode. The process gas pressure was monitored by a capacitive manometer in a closed loop with a downstream throttle valve and was set at $30 \mathrm{~Pa}$. The applied power was always $500 \mathrm{~W}$, while the process temperature ranged from 40 to $80{ }^{\circ} \mathrm{C}$ (see caption to Fig. 2). The etching gases $\left(\mathrm{O}_{2}, \mathrm{He}\right.$ and $\mathrm{CCl}_{2} \mathrm{~F}_{2}$, or their mixtures) were supplied through stainless steel lines operated by mass flow controllers with an average flow rate of about $250 \mathrm{sccm}$.

Atomic force microscopy (AFM) measurements were done with a SOLVER P-4 (NT-MDT) microscope operating in the tapping mode with a standard cantilever (NSG111) [6], selected images are given in Fig. 2.

Static secondary ion mass spectrometry (SIMS) was carried out in a "Shipovnik" (NITI) installation at the bare vacuum $<7 \times 10^{-8} \mathrm{~Pa}$ [9]. The analytical conditions were as follows: primary ions: $\mathrm{O}_{2}{ }^{+}$, differentially pumped duoplasmatron type source with a cold cathode, impact angle: $60^{\circ}$, primary ion energy: $10 \mathrm{keV}$ using the Wien filter, beam current: $200 \mathrm{nA}$, raster size: $400 \mu \mathrm{m} \times 400 \mu \mathrm{m}$, beam diameter: $30 \mu \mathrm{m}$, working vacuum: $3 \times 10^{-7} \mathrm{~Pa}$. The positive secondary ions were detected by a quadrupole mass spectrometer adjusted to the range of $0-200 \mathrm{~m} / \mathrm{z}$. The best mass sensitivity obtained for this equipment in the given conditions was $5 \times 10^{-6}$ calibrated from $\mathrm{B}^{+}$ ions in a $\mathrm{Si}$ solid matrix, with the mass resolution of $0.1 \mathrm{~m} / \mathrm{z}$. The samples were analyzed without pretreatment, no charge compensation was needed for all $\mathrm{PcCu}$ films.

The data acquisition and treatment were performed using the software coming with the spectrometer. The program includes consecutive refinement from singlepoint peaks, smoothing (the procedure is based on the moving mean method) and peak deconvolution, so the vertical bar chart is finally constructed. The SIMS spectra of initial (a), sputtered (b) and variously etched $\mathrm{PcCu}$ films (c-e) are shown in Fig. 3. The SIMS patterns were somewhat oversaturated, we will therefore focus on the peaks with the height of ca. $10^{3}$ and above, and on elements of particular interest. The $x$ axis is limited by instrumental settings. Some peak coordinates are given in Table 2.

The data are represented "as is" (without normalization [10]). Possible matrix effects and relative secondary ion yields are not taken into account here. 

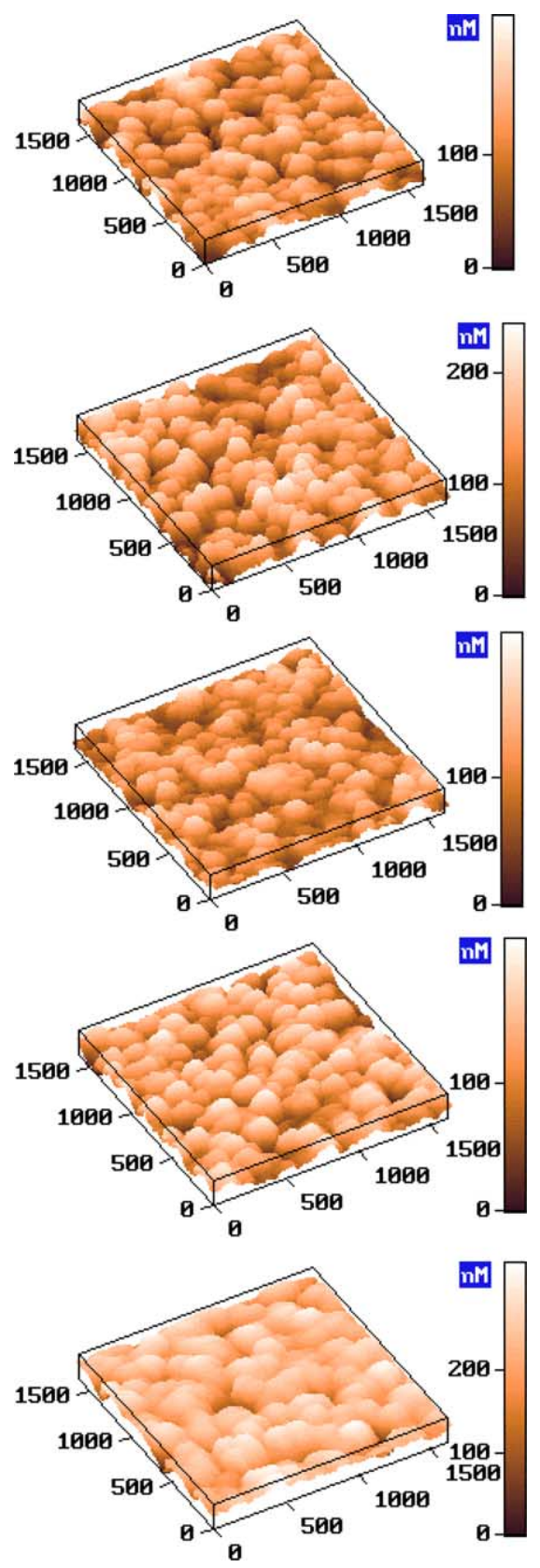

Fig. 2. AFM images of PcCu films, top to bottom: (a) intact surface, (b) etched in pure $\mathrm{He}$ for $1.5 \mathrm{~min}$ at $40{ }^{\circ} \mathrm{C}$, (c) etched in a mixture of $\mathrm{He}: \mathrm{CCl}_{2} \mathrm{~F}_{2}=1: 1$, (d) etched in pure $\mathrm{CCl}_{2} \mathrm{~F}_{2}$ for 3 min at $80{ }^{\circ} \mathrm{C}$, (e) etched in pure $\mathrm{O}_{2}$ for $1.5 \mathrm{~min}$ at $80{ }^{\circ} \mathrm{C}$ (other conditions-see Section 2).
Although these may also affect the spectra of molecular films (see, e.g. [11]), there are no reliable literature data for correction. We are interested in the relative changes in samples and in detection of certain components within a spectrum rather than in a quantitative analysis of an organic solid with SIMS.

\section{Results and discussion}

\subsection{The film topology}

The intact film surface consists of rounded grains with the diameter $(D)$ distribution approximately from 95 to $120 \mathrm{~nm}$ (Fig. 2a, Table 1). The mean peak height $\left(Z_{\mathrm{p}}\right)$ is $58 \mathrm{~nm}$, while the surface roughness $\left(Z_{\mathrm{R}}\right)$ is $32 \mathrm{~nm}$. These values are greater than those reported in [12] for similar systems, obviously owing to the differences in the film thickness and deposition rates. The surface roughness of initial Si-wafers prior to the deposition of organic films was less than $0.5 \mathrm{~nm}$.

Treatment in He plasma led to an increase of the grain height and $Z_{\mathrm{R}}$ (see, Table 1 and Fig. $2 \mathrm{~b}$ ). As the distribution of the grain sizes is broad, it is hard to decide whether the grain diameter decreases or not. Besides, AFM measurements were made not exactly on the same area of the film surface, so possible variation in the topology along the film surface should be taken into account.

Adding dichlorodifluoromethane to the He plasma had little effect on the film surface (see Fig. 2c, Table 1). The roughness somewhat decreased in comparison with the previous two samples. A trend towards cluster association can be noticed.

The subsequent increase in the concentration of reactive etchant in plasma up to $100 \%$ was not efficient for altering the film relief. Then, the temperature

Table 1

AFM statistics

\begin{tabular}{lrll}
\hline Fig. 2 & $D(\mathrm{~nm})$ & $Z_{\mathrm{p}}(\mathrm{nm})$ & $Z_{\mathrm{R}}(\mathrm{nm})^{\mathrm{a}}$ \\
\hline $\mathrm{a}$ & $95-120$ & 58 & 29 \\
$\mathrm{~b}$ & $90-115$ & 92 & 35 \\
$\mathrm{c}$ & $85-140$ & 72 & 26 \\
$\mathrm{~d}$ & $100-150$ & 68 & 30 \\
$\mathrm{e}$ & $180-220$ & 80 & 32 \\
\hline \multicolumn{2}{c}{${ }^{\mathrm{a}}$ Calculated } \\
$Z_{\mathrm{ij}}-Z_{\mathrm{p}}$.
\end{tabular}




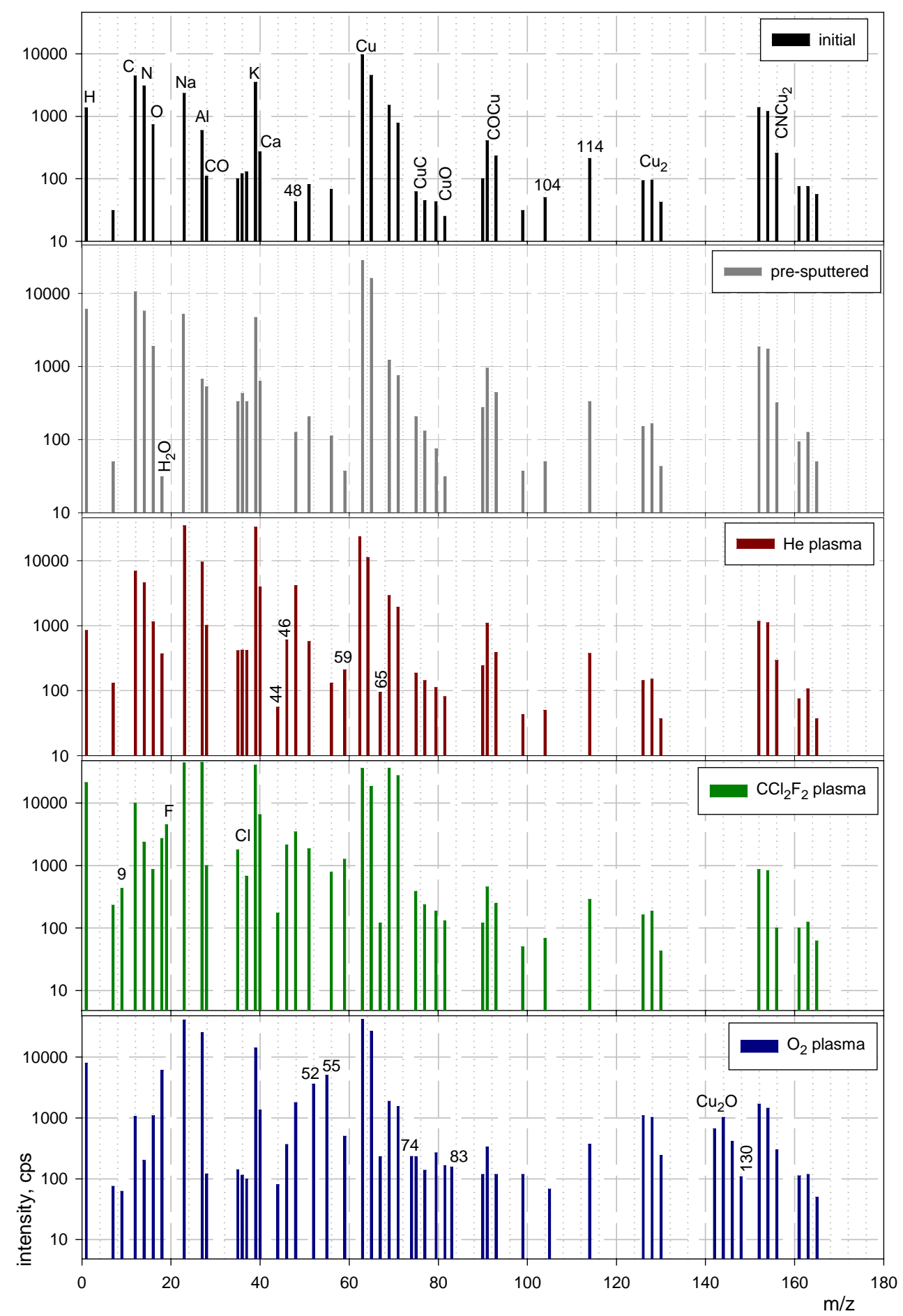

Fig. 3. SIMS spectra (top to bottom): (a) initial PcCu film (Fig. 2a), (b) pre-sputtered surface, (c) corresponds to the sample shown in Fig. 2b, (d) as in Fig. 2d, (e) as in Fig. 2e. The labeled peaks are discussed in the text, those without labels remain unexplained. 
of the reaction chamber was increased to $80{ }^{\circ} \mathrm{C}$ and the films were etched in pure $\mathrm{CCl}_{2} \mathrm{~F}_{2}$ for $3 \mathrm{~min}$ in order to attain an appreciable modification. As follows from Fig. 1d, after such a treatment the grain diameter becomes larger, but the vertical contrast is almost unaffected (Table 1). One can notice a slight faceting of the grains, which is typical for annealed PcM films $[8,12]$.

The use of oxygen plasma under the same conditions as in the previous experiment causes most pronounced modification (see Fig. 1e). $D$ increases 1.5 times (Table 1), while $Z_{\mathrm{p}}$ becomes equal to $80 \mathrm{~nm}$. The surface roughness is virtually slightly altered, which is connected with diminution of the amount of peaks per surface area (see footnote to Table 1). In addition, the film contains deep holes (possibly up to the substrate). Etching in $\mathrm{O}_{2}$ for 3 min results in total stripping of the organic film off the substrate.

\subsection{The SIMS analysis of the surface}

Common methods for investigation of modified PcMet films like XPS or FT-IR yield many useful data $[10,13-16]$. Nevertheless, SIMS is very appropriate because it allows observing organic molecular ions, even thermally labile, with high sensitivity on the surface and in the film bulk [17]. A decided disadvantage, especially for the already modified solids, consists in the interference of species typical of the analyzed sample, with possibly similar secondary ions produced by the primary ion impact itself [18]. Rearrangement of fragments may occur during sputtering and ionization, which complicates identification of the spectral features, too. A cautious attempt to assign the most prominent SIMS peaks is made below based on comparison with the literature data on SIMS and mass spectra of PcM [13,19-23].
First, let us discuss the initial $\mathrm{PcCu}$ film spectrum (see Fig. 3a). All ions of the basic elements composing the molecular formula of the parent compound, i.e., $\mathrm{H}$, $\mathrm{C}, \mathrm{N}, \mathrm{Cu}$ are readily detected (Table 2), as well as common metallic impurities such as $\mathrm{Na}, \mathrm{K}, \mathrm{Al}, \mathrm{Ca}$, which SIMS is very sensitive to [20]. Oxygen ions are inevitably present in all spectra. They may come either from absorbed species, or from forward implantation. The latter reason determines apparently the presence of oxygen-containing positive clusters at $28 \mathrm{~m} / \mathrm{z}, 79 / 81$ (doublet) $\mathrm{m} / \mathrm{z}$ and $91 / 93$ (doublet) $\mathrm{m} / \mathrm{z}$, which are interpreted as $\mathrm{CO}, \mathrm{CuO}$ and $\mathrm{COCu}$, respectively.

Traces of organic impurities related to the sample history, such as phthalodinitrile and phthalic acid, or metal free phthalocyanine (possible metal loss, e.g. during sublimation) were not found. The peak at 104 $\mathrm{m} / \mathrm{z}$ is characteristic of the mass spectra of phthalic acid (corresponds to $\mathrm{C}_{7} \mathrm{H}_{4} \mathrm{O}^{+}$) [23], but may be due to the primary particles bombardment. The origin of the peaks at $35-37 \mathrm{~m} / \mathrm{z}$ is not completely clear. Presumably, there is a contribution of chlorine, either as incidental substituent of hydrogen in Pc-ligand, or as admixture remaining after the synthesis [24].

As follows from the SIMS patterns in Fig. 3a-e, copper ions and clusters play a dominant role in the chosen spectral range. One explanation could be a higher relative yield of secondary ions, which is, for pure matrix materials, by more than 1.5 order of magnitude greater for $\mathrm{Cu}^{+}$than for light ions $\mathrm{C}^{+}$, $\mathrm{N}^{+}, \mathrm{O}^{+}$. In addition to a well-resolved doublet at 63/65 $\mathrm{m} / \mathrm{z}$ (intensity ratio 7:3) typical of $\mathrm{Cu}^{+}$with natural isotopic abundance, an intense triplet was detected in the range of $152-156 \mathrm{~m} / \mathrm{z}$ (Fig. 2a). It was identified as a positive cluster $\mathrm{CNCu}_{2}$. Similar clusters $\left(\mathrm{CNCO}_{2}{ }^{+}\right)$ were observed in the SIMS spectra of PcCo powders [20]. The presence of $\mathrm{CNCu}^{+}$ions is not so evident as there are other peaks in this region (see Fig. 3a). Furthermore, the triplet at $126-130 \mathrm{~m} / \mathrm{z}$ can be

Table 2

Intensities (cps) of some peaks corresponding to element constitutents of a $\mathrm{PcCu}$ molecule (see, Fig. 1)

\begin{tabular}{|c|c|c|c|c|c|c|c|}
\hline Sample in & & Figs. $2 \mathrm{a}$ and $3 \mathrm{a}$ & Fig. $3 b$ & Figs. $2 \mathrm{~b}$ and $3 \mathrm{c}$ & Fig. 2c & Figs. $2 d$ and $3 d$ & Figs. $2 \mathrm{e}$ and $3 \mathrm{e}$ \\
\hline \multirow[t]{4}{*}{ Positive ion } & $\mathrm{Cu}(63)$ & 9600 & 25100 & 23100 & 22800 & 35800 & 41800 \\
\hline & $\mathrm{N}(14)$ & 3100 & 5800 & 4600 & 2200 & 2400 & 300 \\
\hline & $\mathrm{C}(12)$ & 4500 & 10500 & 6900 & 7700 & 10000 & 1100 \\
\hline & $\mathrm{H}(1)$ & 1400 & 6100 & 900 & 5100 & 21100 & 7900 \\
\hline
\end{tabular}


attributed to $\mathrm{Cu}_{2}{ }^{+}$. If the triplet at $161-165 \mathrm{~m} / z$ in the right part of Fig. 3a-e also corresponds to a particle composed of two copper atoms, then the organic residue must correspond to $35 \mathrm{~m} / \mathrm{z}$, that is difficult to interpret. The nearest known case would be a positive ion with a structure $[1 / 4 \mathrm{Pc}+$ metal $\mathrm{CN}]^{+}$giving a doublet at $165 \mathrm{~m} / z$ [22]. Finally, a less intense doublet at $75 / 77 \mathrm{~m} / z$ is associated with $\mathrm{CuC}^{+}$ $\left(\mathrm{CuO}^{+}\right.$and $\mathrm{COCu}^{+}$are mentioned above).

Speculation on the relative intensities (isotopic ratios) of neighboring maximums in these multiplets is generally complicated because of a diffuse nature of the peaks and mutual overlapping. For example, the peak at $128 \mathrm{~m} / z$ in the $\mathrm{Cu}_{2}{ }^{+}$triplet is relatively more intense than the others (Fig. 3a-e). This can be thought to be due to the contribution of the phthalodinitrile ion $\left(\mathrm{C}_{8} \mathrm{H}_{4} \mathrm{~N}_{2}{ }^{+}, M=128\right)$, which is often reported for SIMS [25] and MS patterns of PcM [22]. It may originate from the charged shiver of phthalocyanine organic ligand (1/4Pc - see, Fig. 1) or, as a molecular ion, from an admixture.

There is also a strong doublet at $69 / 71 \mathrm{~m} / \mathrm{z}$, whose position and relative intensity visually match the $\mathrm{Ga}^{+}$ ion. It is an unexpected impurity even for the material of technical grade. Other techniques (X-ray photoelectron spectroscopy [8]) did not reveal this element in remarkable amounts. Additionally, by comparing between the samples (Fig. 2a-d) one can see that the intensity of these peaks is essentially not constant.

The peak at $114 \mathrm{~m} / \mathrm{z}$ is attributed to benzopyrrole (izo-indole) fragments of the $\mathrm{PcCu}$ molecule. They can be formed by symmetrical breaking of a four-leaf organic ligand with detachment of bridging (outer) nitrogen atoms (Fig. 1). Since this peak was not observed in conventional mass spectra of PcM, we assume that such fragmentation is caused by the primary ion impact. Note that this peak is stable whatever the sample.

The Pc-ligand has a high carbon content (32 of 56 atoms), so the peak at 48 is assumed to relate to $\mathrm{C}_{4}{ }^{+}$. Perhaps, such peaks with small $\mathrm{m} / z$ numbers (e.g. 51, 56) may also be due to multiply charged or dehydrogenated ions.

As shown elsewhere [20,22,26], positive mass and SIMS spectra of metal phthalocyanines usually exhibit peaks corresponding to variously charged molecular ion, detached metal, secondary and quaternary molecular fragments $1 / 2 \mathrm{Pc}$ and $1 / 4 \mathrm{Pc}$, and ions formed by the loss of the nitrile group. With the exception of clusters containing metal atoms, which are clearly distinguishable by isotopic distribution, all these ions have even mass numbers, when singly charged. Peaks with odd mass numbers would be expected for metal free phthalocyanine, where, similarly to the indole or pyrrole derivatives, loss of hydrogen or HCN group is characteristic [27]. Hence, the detected peaks at 7, 51, 59, 99 and some others are most likely associated with re-arranged or multiply ionized clusters.

Next, the SIMS spectrum of the initial $\mathrm{PcCu}$ film was recorded once again from the same raster area after the first scan (i.e., from the pre-sputtered surface) (Fig. 3b). Basic relative ratios of ions and clusters in this case are approximately similar to those from the uppermost layer (Table 2). Appearance of a weak signal of $\mathrm{H}_{2} \mathrm{O}^{+}$ion and overall increase of the peak intensities (Fig. 3b, Table 2) are registered. As the high vacuum was not broken at these stages, the former feature implies that the water ions are indeed formed by forward implantation of oxygen. The latter feature points towards a better yield from the pre-sputtered surface.

Second, let us discuss the changes in the SIMS pattern occurring after plasma irradiation of $\mathrm{PcCu}$ films. Several distinctive features should be mentioned here. For all etched samples $\mathrm{H}_{2} \mathrm{O}^{+}$species were detected. This means that the surface of these films exposed to air from the etcher before SIMS measurements intensively adsorbs water. As in the AFM images no important increase in the surface area is seen (Fig. 2, Table 1). The retention of water is possibly related to the chemical activity of the modified surface. None of the peaks typical of the intact $\mathrm{PcCu}$ film surface disappeared (Fig. 3c-e, Table 2) or significantly changed relative to each other (except etching in oxygen). We therefore assume that the film surface is still composed dominantly of phthalocyanine molecules.

On the other hand, SIMS patterns for etched $\mathrm{PcCu}$ films are richer, especially in the small $\mathrm{m} / \mathrm{z}$ numbers domain. Appearance of new peaks at 44 (possibly, $\left.\mathrm{CO}_{2}{ }^{+}[21]\right), 46,59,65 \mathrm{~m} / \mathrm{z}$ was detected, while the intensity of peaks at 18, 27, 48, 56, 69, $71 \mathrm{~m} / \mathrm{z}$ increased. Higher intensity of the $\mathrm{Al}^{+}$signal (Fig. 3c-e) can reasonably be attributed to possible contamination from the walls of reaction chamber. For the film etched in $\mathrm{CCl}_{2} \mathrm{~F}_{2}$ (Fig. 3d) the well-resolved 
chlorine isotopic doublet at $35 / 37 \mathrm{~m} / \mathrm{z}$ and the peak of fluorine ions at $19 \mathrm{~m} / \mathrm{z}$ were detected together with a rise of a relative $\mathrm{C} / \mathrm{N}$ ratio. However, the peaks expected for a dichlorodifluoromethane molecular ion or its fragments were not found. This implies that atoms (or groups) of dichlorodifluoromethane are chemically bound to phthalocyanine molecules. In the case of oxygen treated films the situation is more complicated. The $\mathrm{Cu}^{+}$signal is most intense in this case, whereas $\mathrm{C}$ and $\mathrm{N}$ signals are very weak (compare Fig. 3, Table 2). A new strong multiplet at $142-146 \mathrm{~m} /$ $z$ was detected, which can be assigned to $\mathrm{Cu}_{2} \mathrm{O}^{+}$. Although oxygen was used as a primary ion, these peaks were missing in all other samples (Fig. 3a-d). The presence of a copper oxide on the surface of the organic film stands for destruction of $\mathrm{PcCu}$ molecules. Further etching in thicker films can be slowed by the growing inorganic by-product. Besides, occurrence of a multiply ionized molecular ion $\mathrm{PcCu} /+4$ in this range can also be hypothesized.

\subsection{The SIMS profiling}

In the final stage, the SIMS profiling of the studied samples has been curried out. The total sputtering time required to reach the substrate (checked by abrupt increase of $\mathrm{Si}$ signal and simultaneous drop of the intensity of other peaks) was ca. $1.1 \times 10^{-3} \mathrm{~s}$ for the initial $\mathrm{PcCu}$ film. Nearly the same time was used for profiling of the film treated in the He plasma. The substrate boundary was degraded in the latter case, which correlates with the increased surface roughness of this sample (compare Fig. 2b) [28]. For both initial and etched samples the distribution of $\mathrm{C}^{+}, \mathrm{N}^{+}$and $\mathrm{Cu}$ species was homogeneous all through the film. Meanwhile, the profiling of the film etched in dichlorodifluoromethane was considerably longer-ca. $1.5 \times 10^{-3} \mathrm{~s}$. This suggests hardening of the film by plasma irradiation. The content of $\mathrm{Cu}$ in the uppermost layer was higher than in the bulk of the film. The profiling of the $\mathrm{PcCu}$ films treated in oxygen plasma took ca. $6 \times 10^{-2} \mathrm{~s}$, whereas the residual film is two times thinner (by interferometry and AFM). The derived etching rate is about $5 \mathrm{~nm} / \mathrm{s}^{1}$ Again, the surface is enriched with copper atoms.

\footnotetext{
${ }^{1}$ For comparison, the rate of $5 \mathrm{~nm} / \mathrm{min}$ for plasma etching of $\mathrm{PcCu}$ in $100 \% \mathrm{O}_{2}$ was reported in [15] (150 W rf power).
}

\section{Conclusion}

As known, the structural perfection of PcM molecules makes them very stable to fragmentation under various impacts [29]. The bombardment with energetic particles leads to destruction of the molecules, up to carbonization of the layer [30]. It is assumed that stable intermediate fragmentation of PcM molecules may occur when chemical bonds are broken under moderate irradiation $[8,13,15,20]$. Appearance of "new" structural species (subunits) detected by SIMS, would mean that the fragmentation is definite. However, treatment both with non-reactive $(\mathrm{He})$ and reactive etchant $\left(\mathrm{CCl}_{2} \mathrm{~F}_{2}\right)$ revealed good withstandability of thin sublimed PcCu films. Effect of oxygen plasma is stronger, which is displayed in both quick removal of the film and chemical degradation of organic material. This opens opportunities for application of this method to fabrication of complex PcMbased heterostructures by means of plasma processing technology.

\section{Acknowledgements}

Authors thank Dr. V.I. Shashkin for many stimulating discussions. This work was in part supported by RFBR grant no. 17407 and programs of the Presidium of the RAS.

\section{References}

[1] T. Tsutsui, K. Fujita Adv. Mater. 14 (2002) 949; D. Cahen, G. Hodes, Adv. Mater. 14 (2002) 789.

[2] C.M. Fischer, M. Burghard, S. Roth, Mater. Sci. Forum 191 (1995) 149;

M.C. Hersam, N.P. Guisinger, J.W. Lyding, J. Vac. Sci. Technol. A 18 (Part 1) (2000) 1349;

P. Ball, Nanotechnology 13 (2002) R15;

M. Macucci, G. Iannaccone, J. Greer, J. Martorell, D. Sprung, A. Schenk, I. Yakimenko, K.F. Berggren, K. Stokbro, N. Gippius, Nanotechnology 12 (2001) 136.

[3] G. Guillaud, J. Simon, J.P. Germain, Coord. Chem. Rev. 180 (1998) 1433;

C.G. Claessens, J.W. Blau, M. Cook, M. Hanack, R. Nolte, T. Torres, D. Wohrle, Monatsh. Chemie 132 (2001) 3.

[4] M.A. Hartney, D.W. Hess, D.S. Soane, J. Vac. Sci. Technol. B 7 (1989) 1.

[5] K. Asakawa, T. Yoshikawa, S. Kohmoto, Y. Nambu, Y. Sugimoto, Jpn. J. Appl. Phys. 37 (Part 1) (1998) 373. 
[6] G.L. Pakhomov, N.V. Vostokov, V.M. Daniltsev, V.I. Shashkin, Phys. Low-Dim. Struct. 5-6 (2002) 247.

[7] B. Gorowitz, R.J. Saia, Reactive Ion Etching, in: N.G. Einspruch, D.M. Brown (Eds.), VSLI Electronics Microstructure Science, vol. 8, Plasma Processing for VSLI, Academic Press, New York, 1984 (Chapter 8).

[8] G.L. Pakhomov, L.G. Pakhomov, V.I. Shashkin, J.M. Tura, J.M. Ribo, L. Ottaviano, Nucl. Instr. \& Meth. Phys. Res. B 194 (2002) 269;

G.L. Pakhomov, Y.N. Drozdov, Cryst. Eng. 6 (2003) 23.

[9] D.M. Gaponova, V.M. Danil'tsev, M.N. Drozdov, et al., Izv. Akad. Nauk, ser. Fiz. 63 (2000) 377.

[10] M. Utsumi, N. Matsukaze, A. Kumagai, Y. Shiraishi, Y. Kawamura, N. Furusho, Thin Solid Films 363 (2000) 13.

[11] T. Nonaka, T. Date, S. Tomita, N. Nagai, M. Nishimura, Y. Murata, A. Ishitani, Thin Solid Films 237 (1994) 87.

[12] L. Grzadziel, J. Zak, J. Szuber, Thin Solid Films 436 (2003) 70.

[13] M. Naddaf, S. Chakane, S. Jain, S.V. Bhoraskar, A.B. Mandale, Nucl. Instr. \& Meth. Phys. Res. B 194 (2002) 54.

[14] S. Robinet, M. Guaneau, M. Salvi, C. Clarisse, R. Chaplain, J. Appl. Phys. 68 (1990) 66;

S. Robinet, M. Guaneau, M. Salvi, C. Clarisse, M. Delamar, M. Leclerc, Thin Solid Films 200 (1991) 385.

[15] H. Sakata, J. Appl. Phys. 89 (2001) 7711.

[16] E.F. Reznikova, S.A. Prokhorova, T.V. Basova, B.M. Ajupov, V.P. Naz'mov, O.A. Makarov, I.K. Igumenov, J.H. Krieger, Nucl. Instr. \& Meth. Phys. Res. A 359 (1995) 415.

[17] A. Benninghoven: Organic secondary ion mass spectrometry, in: A. Benninghoven, J. Okano, R. Shimizu, H.W. Werner (Eds.), SIMS IV, Springer, Berlin, 1984, pp. 343-355.
[18] E.E. Johnston, B. Ratner, J. Electron Spectr. Relat. Phenom. 81 (1996) 303.

[19] M. Benkaddour, O. Elbeqquali, M. Alsadoun, M. Gamoudi, G. Guillaud, Synth. Met. 40 (1991) 29;

A. Wilson, G.P. Rigby, J.D. Wright, S.C. Thorpe, T. Terui, Y. Maruyama, J. Mater. Chem. 2 (1993) 303.

[20] G. Lalande, R. Cote, G. Tamizhmani, G. Guay, J.P. Dodelet, L. Dignard-Bailey, L.T. Weng, P. Bertrand, Electrochim. Acta 40 (1995) 2635;

L.T. Weng, P. Bertran, G. Lalande, D. Guay, J.P. Dodelet, Appl. Surf. Sci. 84 (1995) 9.

[21] K. Yase, Y. Yoshida, T. Uno, H. Okui, J. Cryst. Growth 166 (1996) 942.

[22] D.D. Eley, D.J. Hazeldine, T.F. Palmer, J. Chem. Soc.: Faraday Trans. 269 (1973) 1808.

[23] Data from NIST Mass Spectrometry Data Center, http:// www.nist.gov.

[24] A. Wilson, R.A. Collins, Phys. Status Solidi (A) 98 (1986) 633.

[25] T.J. Schuerlein, N.R. Armstrong, J. Vac. Sci. Technol. A 12 (Part 2) (1994) 1992.

[26] D.J. Dale, A.C. Jones, P. Langridge-Smith, K.F. Costello, P. Cummins, Anal. Chem. 65 (1993) 793.

[27] H. Budzikievicz, C. Djerassi, D.H. Williams, Interpretation of Mass Spectra of Organic Compounds, Holden-day Inc., San Francisco, 1964.

[28] W. Bijnens, J. Manca, T.D. Wu, M.D. Olieslaeger, D. Vanderzande, J. Gelan, W. DeCeuninck, L. DeSchepper, L.M. Stals, Synth. Met. 83 (1996) 261.

[29] M.L. Kaplan, S.R. Forrest, P.H. Schmidt, T. Venkatesan, J. Appl. Phys. 55 (1984) 732.

[30] A. Nath, M.J. Prushan, J.G. Gilbert, J. Radioanal. Nucl. Chem. 247 (2001) 589. 